\title{
Helena Antipoff e a Fazenda do Rosário: a educação pelo trabalho de meninos "excepcionais" na década de 1940*
}

\section{Helena Antipoff and the Rosário Farm: the education by the work for the "exceptional" children and adolescents in 1940s}

\author{
Heulalia Charalo Rafante', Roseli Esquerdo Lopes²
}

RAFANTE, H. C.; LOPES, R. E. Helena Antipoff e a Fazenda do Rosário: a educação pelo trabalho de meninos "excepcionais" na década de 1940. Rev. Ter. Ocup. Univ. São Paulo, v. 19, n. 3, p. 144-152, set./dez. 2008.

\begin{abstract}
RESUMO: Trata-se de uma pesquisa histórica, baseada em fontes documentais, cuja análise buscou fazer emergir a história da Fazenda do Rosário, instituição criada em 1940, pela psicóloga e educadora russa Helena Antipoff, para receber, em regime de internato, meninos "excepcionais" de Belo Horizonte. Observou-se as ações pedagógicas, o perfil e a trajetória dos internos, além das reações ao processo de institucionalização - entendido como um instrumento dos setores dominantes da sociedade para conservar a ordem vigente, no sentido de detectar o diferente e isolá-lo, numa estrutura de organização social que produz a contradição. Verificou-se, com relação às ações empreendidas por Helena Antipoff, se atenderam às necessidades das crianças e dos adolescentes institucionalizados ou se constituíram enquanto resposta ao meio social em que se instalou a instituição. Concluiu-se que a formação dos meninos tinha por objetivo prepará-los para o trabalho e o fio condutor das atividades foi o próprio trabalho, que substituía os estudos e as brincadeiras e os obrigava a se comportarem como adultos trabalhadores. Essa educação visava à produção da adaptação dos internos a uma realidade social pré-estabelecia, sendo, portanto, a educação 'apenas' um meio para, de fato, proteger e conservar o ordenamento social.
\end{abstract}

DESCRITORES: Educação especial. Trabalho. Criança institucionalizada/educação. Institucionalização. Pessoas com Deficiência/história.

\footnotetext{
* Este artigo é um dos desdobramentos da dissertação de mestrado intitulada "Helena Antipoff e o Ensino na Capital Mineira: a Fazenda do Rosário e a Educação pelo Trabalho dos Meninos 'Excepcionais' de 1940 a 1948”, desenvolvida no Programa de Pós-Graduação em Educação, da Universidade Federal de São Carlos (UFSCar), pela primeira autora com a orientação da segunda autora, tendo contado com o apoio da Coordenação de Aperfeiçoamento de Pessoal de Nível Superior - CAPES.

1. Historiadora pela Universidade Federal de Ouro Preto, Mestre em Educação pela UFSCar, Doutoranda em Educação pela UFSCar. Integrante do Grupo de Pesquisa Terapia Ocupacional e Educação no Campo Social. Bolsista CNPq.

2. Terapeuta Ocupacional pela Universidade de São Paulo (USP), Especialista em Saúde Pública pela USP, Mestre em Educação pela UFSCar e Doutora em Educação pela Universidade Estadual de Campinas. Professora Associada do Departamento de Terapia Ocupacional e do Programa de Pós-Graduação em Educação da UFSCar. Coordenadora do Grupo de Pesquisa Terapia Ocupacional e Educação no Campo Social. Pesquisadora do CNPq.

Endereço para correspondência: Laboratório METUIA do Departamento de Terapia Ocupacional da UFSCar. Via Washington Luis, km 235 - São Carlos, SP. CEP: 13565-905._heulaliarafante@yahoo.com.br e relopes@ufscar.br
} 


\section{INTRODUÇÃO}

Fazenda do Rosário foi criada em 1940 para
receber meninos "excepcionais" de Belo
Horizonte, atendidos pela Sociedade Pestalozzi de Minas Gerais, cuja presidente era Helena Antipoff. O objetivo deste estudo foi reconstituir os primeiros anos da história da Fazenda do Rosário, a partir da análise das ações pedagógicas, do perfil e da trajetória dos internos, da repercussão desses processos para os institucionalizados, buscando verificar se as ações empreendidas atenderam às necessidades dos "excepcionais" ou constituíram-se enquanto resposta ao meio social onde se instalou essa instituição, a sociedade mineira das décadas de 1930 e 1940.

O texto apresenta a trajetória de Helena Antipoff desde a Rússia, sua passagem pela França e Suíça (1908-1916), a volta para a Rússia (1916-1924) e depois para a Suíça (1925-1927), até receber o convite para trabalhar em Minas Gerais, no âmbito da Reforma de Ensino Francisco Campos (1927). Nesse percurso, buscou-se compreender quais experiências e princípios científicos constituíram a base que orientou a prática da educadora, bem como conhecer as motivações para a criação de instituições para atender às crianças "excepcionais".

Realizamos pesquisa documental a partir dos escritos de Helena Antipoff com resultados de pesquisas, palestras, conferências, seminários. Consultamos os diários das professoras e os relatórios da diretora da instituição. Inicialmente, o recorte temporal foi de 1940 a 1948, período em que as atividades da Fazenda do Rosário foram dedicadas exclusivamente aos "'excepcionais". Em 1948, a instituição passou a contemplar a educação rural e a formação de professores. No entanto, encontramos documentos que nos levaram a um retrato do atendimento aos "excepcionais" até 1952 e, devido à riqueza documental, ampliamos o período da pesquisa, mantendo o foco no atendimento aos "excepcionais".

Nos doze anos estudados, verificamos que o trabalho foi o fio condutor do processo educativo. Investigamos como se deu essa educação pelo e para o trabalho, em que as atividades escolares ficavam em segundo plano e o trabalho substituía os estudos e as brincadeiras, obrigando crianças e adolescentes a se comportarem como adultos trabalhadores.

Helena Antipoff foi uma das pioneiras na sistematização do atendimento aos "excepcionais" brasileiros e os princípios praticados nas instituições por ela criadas nas décadas de 1930 e 1940 influenciaram a educação dos "excepcionais" nas décadas seguintes, com a importante participação da educadora na organização de ações governamentais na área da Educação Especial, como a Campanha Nacional de Educação e Reabilitação de Deficientes Mentais CADEME - na década de 1960 e a criação do Centro Nacional de Educação Especial - CENESP - na década de 1970. Diante da importância da ação da educadora no campo da educação do "excepcional", torna-se relevante o resgate da história da Fazenda do Rosário.

\section{A QUESTÃO DA INSTITUCIONALIZAÇÃO}

Partimos da categoria institucionalização, formulada por Franca e Franco Basaglia (1977) que, considerando a divisão de classes engendrada pelo modo de produção capitalista, destacam que a aceitação dessa divisão como fenômeno natural exige regras e instituições que, aparentemente destinadas a resolver as contradições, servem para manter a divisão original sob a qual se ergue o sistema capitalista. O processo de institucionalização é um instrumento dos setores dominantes da sociedade para conservar a ordem vigente, no sentido de detectar o diferente e isolá-lo, buscando esconder o fato de que é a estrutura da organização social que produz a diferença São considerados diferentes os indivíduos que por não produzirem são excluídos da sociedade. A estratégia é estabelecer o diferente a priori, possibilitando aplicar a definição mais adequada para justificar uma intervenção repressiva, sendo que os mecanismos de intervenção ou instituições de violência são os presídios, manicômios, institutos terapêuticos, de controle, de reabilitação e segregação em que, através da mistificação da terapia e da reabilitação, obtém-se a conservação da ordem pública, o ritmo produtivo e a eficiência da organização social. Considerando esses pressupostos, levantamos a questão de pesquisa: as ações empreendidas por Helena Antipoff atenderam às necessidades dos "excepcionais" institucionalizados ou constituíram-se enquanto resposta ao meio social?

Esse referencial aponta dois caminhos para o técnico que atua no processo de institucionalização: o técnico pode ser o encarregado de controlar a contenção, justificada pelas ideologias científicas, de forma que a segregação não é resposta para o segregado e sim para a sociedade que criou a instituição; ou, em contraposição, o técnico, por intermédio de sua prática, pode tomar consciência dos mecanismos que fundamentam as instituições e passar a intervir no sentido de que o objeto da manipulação se aproprie dos conhecimentos que justificam seu estado de segregado ao ponto de recusá-los. Nessas condições, o trabalho técnico atua, também, como trabalho político. Diante desses apontamentos, buscamos compreender qual o caminho seguido pelas propostas e ações de Helena Antipoff junto aos "excepcionais" da Fazenda do Rosário. 


\section{HELENA ANTIPOFF: DA RÚSSIA AO BRASIL}

Helena Antipoff, hoje uma referência na história da psicopedagogia brasileira, nasceu na Rússia em 1892 e, em 1908, mudou-se para França. No Laboratório de Psicologia da Universidade de Paris, participou da padronização dos testes de nível mental de crianças, elaborados por Alfred Binet e Théodule Simon. Nesse período, a educadora conheceu Edouard Claparède, que a convidou para fazer parte do Instituto Jean-Jacques Rousseau, na Suíça, onde concluiu o curso de Psicologia, com especialização em Psicologia da Educação.

A experiência profissional de Helena Antipoff teve início na Maison des Petits, escola anexa ao Instituto Jean Jacques Rousseau, sob os princípios da "Escola Sob Medida" e do método de Experimentação Natural. A proposta da "Escola sob Medida" foi desenvolvida por Edouard Claparède e previa que a educação deveria ter como centro dos programas e dos métodos escolares a criança e deveria considerar as aptidões individuais no encaminhamento das práticas pedagógicas (CLAPARÈDE, 1953, p. 167). A "Experimentação Natural" foi desenvolvida pelo psicólogo russo Alexandre Lazurski, a partir da observação dos alunos em suas atividades escolares, e consistia em observar e escolher comportamentos do indivíduo com base em atividades reais e, a cada reação típica, atribuir uma significação caracterológica que, segundo a intensidade da manifestação, avaliava o grau da reação psicológica. Além de estudar o indivíduo em situações reais, o método podia ser aplicado em qualquer ambiente (ANTIPOFF et al., 1958, p. 17). Completavam esse aparato técnico-científico os testes de inteligência elaborados por Alfred Binet e Théodule Simon.

A educadora retornou à Rússia, em 1916, quando trabalhou com crianças órfãs, vítimas da Primeira Guerra e da Revolução Russa. Em São Petersburgo, atuou no CentroMédico Pedagógico, estudando as crianças abandonadas e classificando-as para serem encaminhadas de acordo com seu caráter para instituições pedagógicas e jurídicas. De volta à Genebra, em 1925, foi assistente de Claparède no Laboratório de Psicologia, assumindo o cargo de professora de Psicologia da Criança. Nesse período, desenvolveu intensa produtividade científica e a repercussão de seus trabalhos ultrapassou as fronteiras dos países de língua francesa, sendo convidada pelo governo de Minas Gerais para auxiliar na implantação da Reforma de Ensino, que estava sendo empreendida naquele estado.
Constatamos que as motivações para a vinda de Helena Antipoff ao Brasil foi justamente uma convergência de princípios que motivou os dirigentes mineiros a convidála para atuar junto ao sistema de ensino, visto que, no Regulamento do Ensino Primário, Francisco Campos, autor da reforma, referiu-se aos resultados das pesquisas realizadas no Instituto Jean Jacques Rousseau como soluções definitivas para a educação (RAFANTE, 2006).

\section{HELENA ANTIPOFF E O ENSINO PRIMÁRIO NA CAPITAL MINEIRA NA DÉCADA DE 1930}

Ao chegar ao Brasil, em 1929, Helena Antipoff assumiu o cargo de professora de Psicologia da Escola de Aperfeiçoamento, onde organizou o Laboratório de Psicologia e realizou pesquisas junto aos alunos do ensino primário dos grupos escolares de Belo Horizonte e, ainda, auxiliou no processo de homogeneização das classes desses grupos escolares. De posse de dados advindos dessas atividades, Helena Antipoff fez um diagnóstico do sistema de ensino mineiro, destacando três problemas: 1) a orientação profissional da criança não ocorria nas escolas; 2) a formação física, moral e intelectual incompleta das crianças ao saírem da escola primária; 3) as crianças que se encontravam "em perigo moral"(1)1. Para a educadora, esses problemas estariam relacionados à duração da escolaridade que, se comparada com países da América do Norte e da Europa, era menor (ANTIPOFF, 1992b). Principalmente, o problema da criança "em perigo moral" seria resultado do próprio sistema de ensino, devido à permanência da pedagogia tradicional e o caminho proposto por Helena Antipoff foi a pedagogia experimental, baseada na experimentação contínua:

Jamais a educação se tornará a cura que dela espera a sociedade e os governos para diminuir, num futuro mais ou menos próximo, o rebotalho humano miserável, que enche os hospitais, os manicômios, as prisões, se ela não abandonar o mais depressa possível seu diletantismo superficial e não se transformar numa arte precisa aplicada ao melhoramento da raça humana e munida dos meios que lhe forja a ciência, que nunca se cansa de as aperfeiçoar (ANTIPOFF, 1992c, p. 49).

Em seu trabalho junto ao sistema de ensino mineiro, Helena Antipoff percebeu que a escola não atendia às

\footnotetext{
(1) $\mathrm{Na}$ concepção de Helena Antipoff, as crianças em "perigo moral” eram aquelas consideradas indisciplinadas, desequilibradas, que apresentam perturbações de caráter e as anti-sociais (ANTIPOFF, 1992, p. 56-57).
} 
necessidades das crianças, justamente por não incorporar os princípios científicos preconizados pela pedagogia experimental. Assim, a educadora direcionou sua atuação no sentido de criar instituições para receber as crianças consideradas "excepcionais", retirando-as do sistema de ensino oficial sob a justificativa de que a escola era responsável pela não adaptação dessas crianças. Em 1932, criou a Sociedade Pestalozzi, associação civil que centralizou as ações direcionadas aos "excepcionais" em Belo Horizonte, que viabilizou o Instituto Pestalozzi (1934), o Pavilhão de Natal (1935) e a Fazenda do Rosário (1940).

No Instituto Pestalozzi, a criança tinha a possibilidade de concluir o ensino primário, além de iniciar um ofício que lhe permitisse o exercício de atividade remunerada ao deixar a instituição. Todavia, não eram todas as crianças que conseguiam concluir o ensino primário ou se profissionalizar, algumas permaneciam no estabelecimento até idade avançada, sem que se conseguisse um "ajustamento social para uma existência menos dependente da família e do Estado" (ANTIPOFF, 1992g, p. 274). Para essas crianças, a Sociedade Pestalozzi adquiriu uma propriedade rural e instalou uma escola-granja, a Fazenda do Rosário (ANTIPOFF, 1992e).

\section{A FAZENDA DO ROSÁRIO E A INSTITUCIONA- LIZAÇÃO DOS MENINOS "EXCEPCIONAIS"}

Situada a $25 \mathrm{~km}$ de Belo Horizonte, a Fazenda do Rosário teve sua direção a cargo de Yolanda Barbosa e Dona Cora, as quais chegaram à Fazenda no início de janeiro de 1940:

Seus começos foram bem modestos: duas professoras - Dona Cora de Faria Duarte e Dona Yolanda Barbosa, com seis meninos do Abrigo de Menores e do Instituto Pestalozzi de Belo Horizonte e mais os primeiros apetrechos domésticos - tudo isso transportado num caminhão - entravam na modestíssima casa de adobes, de chão batido. Sem água encanada, sem luz elétrica, sem instalações higiênicas, a vida dos pioneiros era dura e sem conforto. Precisou muita coragem e devotamento infinito à causa da infância desamparada para agüentar esses difíceis inícios (ANTIPOFF, 1992h, p. 241).

As aulas do curso primário, destinadas aos alunos internos e externos vindos da vizinhança, tiveram início em fevereiro de 1940, com a abertura da Escola Isolada Dom Silvério, que funcionava nas instalações simples da propriedade rural. Apenas em 1944, começou a construção do pavilhão central, onde se instalou, a partir de 1946, a residência dos professores, $o$ internato das crianças, $o$ refeitório, a cozinha, a biblioteca e as salas de aula.

Até 1942, a Fazenda recebia meninos considerados "excepcionais sociais", classificados por sua conduta ou seu caráter, "cujas condições de vida familiar ou social impediam uma adequada estimulação" (CAMPOS, 2002 , p. 22). Incluía meninos abandonados pela família ou pelo responsável. Em 1942, a instituição passou a receber também os "excepcionais orgânicos", aqueles cujo desenvolvimento mental se apresentava aquém ou além do padrão estabelecido para crianças da mesma idade e aqueles portadores de distúrbios de origem hereditária (CAMPOS, 2002, p. 22). De acordo com o relatório da diretora Yolanda Barbosa, para os dois grupos se propunha o mesmo tipo de atividade: o trabalho, mesmo quando considerados não amadurecidos para realizá-lo integralmente.

Em se tratando de menores excepcionais, com retardo mental, outros com instabilidade emocional, com deficiência física ou desajustamentos sociais, poucos eram suficientemente amadurecidos para fazer o trabalho integralmente e com a necessária independência. Na maioria dos casos eram capazes de executar tarefas ou parte do trabalho (ANTIPOFF; BARBOSA, 1992, p. 133).

Além dos seis primeiros internos, a instituição recebia cerca de doze crianças da vizinhança para aulas. A pesquisa documental mostrou que o ensino existia no projeto pedagógico, mas Helena Antipoff destacava como principal proposta de formação a educação voltada para o trabalho, que buscava a "formação de gerações melhor preparadas para a produção técnico-econômica, agrícola e artesanal" (ANTIPOFF, 1992i, p. 171). Vejamos como se efetivou essa proposta na Fazenda do Rosário. Dona Cora relatou em seu diário que as benfeitorias iniciais na propriedade rural foram feitas pelos novos moradores.

(...) começamos nossa 'alta recreação' um movimento de limpeza no sítio. O caminho para o córrego estava intransitável; já agora se pode passar, sem pisar nas ervas. A bica, Iolanda consertou. A frente da casa apresenta melhor aspecto, com as bananeiras limpinhas (DUARTE apud ANTIPOFF, 1952, p. 1).

Os primeiros internos chegaram à Fazenda do Rosário no dia 2 de janeiro de 1940 e, no dia 9, "os meninos receberam a distribuição dos serviços que está à parede da cozinha para lhes lembrar os deveres. Cada qual ficou encarregado de um trabalho, e ontem deram conta satisfatoriamente das obrigações" (MELO apud ANTIPOFF, 1952, p. 2). O dia de trabalho começava cedo para eles, "ontem, às 5 horas e meia da manhã já se ouvia a vozeria 
alegre dos meninos, que já são sete, tomando leite no curral" (MELO apud ANTIPOFF, 1952, p. 2). As atividades escolares propriamente ditas ficavam em segundo plano e não eram priorizadas, dava-se maior destaque ao trabalho agrícola executado pelos meninos:

22/01/40 - Como amanheceu chovendo muito (...) fiquei só com os meninos, os quais não podendo fazer o trabalho de conserto da estrada e capina, ficaram lendo, escrevendo (...) (BARBOSA apud ANTIPOFF, 1952, p. 5).

Destacamos a passagem do diário de Helena Antipoff referindo-se a um aluno que saía da instituição após um ano de permanência, demonstrando sua preocupação com a formação incompleta do menino no período que passou na Fazenda.

11/01/41 - (...) Queria eu que terminasse ao menos o ciclo inteiro da construção que iniciou, britando pedra, devia aprender pelo menos o reboco, a fim de ganhar mais no emprego (ANTIPOFF, 1952, p. 20).

O ciclo inteiro não se referia ao ensino primário completo e sim ao aprendizado da profissão de pedreiro. Apesar dos diários apontarem para a existência de pedreiros adultos, as crianças também ajudavam nas construções dos prédios da instituição.

02/11/40 - (...) Na ausência do "Vovô", o pedreiro, seu filho Floriano está na direção da Casa de Repouso em construção (...). Mas, por que então, Geraldo Lopes estará na lavoura, ele que é tão bom no serviço de pedreiro? Não combinou com Floriano? Na "reunião" trataremos do caso do "abandono espontâneo" do serviço. Mas de quem é a culpa, do menino ou do mestre? (...) (ANTIPOFF, 1952, p. 15).

Inferimos, portanto, que as crianças eram obrigadas a desempenhar o trabalho que lhes era designado e referia-se, principalmente, a atividades agrícolas e à construção civil. Com o intuito de criar o hábito do trabalho e de educar em relação a seus desdobramentos econômicos, foi estabelecido que os meninos seriam remunerados e o valor a ser pago estaria vinculado à prontidão com que desempenhassem o trabalho, ao bom humor, à produção, à iniciativa útil e à invenção de algum processo original que melhorasse a realização do mesmo. Os próprios meninos estabeleciam as bases de julgamento, com a aprovação dos professores. A reunião que definiu a remuneração dos internos ocorreu em 3 de fevereiro de 1940, sendo a primeira do Conselho da Fazenda, que passou a acontecer semanalmente, contando com a participação dos internos, com o objetivo de organizar as atividades da instituição e viabilizar "maior harmonia entre todos e mais estreita colaboração de meninos e adultos, professores, trabalhadores e encarregados dos serviços (...)" (MELO apud ANTIPOFF, 1952, p. 7).

Na reunião do dia 12 de outubro de 1940, foi discutida a implantação das fichas de trabalho individual e do grupo, "a fim de melhor controlar a distribuição dos encargos e dos esforços (...)" (ANTIPOFF, 1952, p. 13). Nessas fichas, os alunos recebiam notas de acordo com o seu desempenho em relação a: rapidez no trabalho, método, perseverança, cuidado com o material, iniciativa, responsabilidade, humor durante o trabalho, habilidade e capricho. Essas fichas serviam de critério para a remuneração, orientavam as professoras no melhor conhecimento dos alunos e os guiava no aperfeiçoamento de suas capacidades e do seu caráter (ANTIPOFF et al., 1958, p.28). A diretora Yolanda Barbosa justificou que o trabalho era utilizado na Fazenda do Rosário para ensinar ofícios para os alunos, mas, principalmente, como meio de educá-los social e moralmente e, por isso, havia a necessidade de controlar suas atividades.

Tomamos o trabalho aqui na escola não somente como um meio de ensinar aos alunos alguns ofícios e técnicas úteis para a sua vida, mas como uma fonte onde pudéssemos melhor conhecê-los, e como um meio poderoso de educá-los social e moralmente (ANTIPOFF; BARBOSA, 1992, p. 130).

O trabalho como meio educativo visava, ainda, conhecer a aptidão de cada interno para determinadas tarefas. A diretora graduou os trabalhos executados pelos meninos semanalmente, apresentando-os a partir do mais simples:

1) - Rasgar palha; 2) - Catar esterco; 3) - Bater esterco; 4) - Transportar lenha; 5) - Debulhar milho; 6) - Varrer o pátio e os caminhos; 7) - Varrer as varandas; 8) - Varrer os refeitórios; 9) - Varrer os quartos; 10) - Tirar poeira; 11) Lavar a casa; 12) - Arrumar as estantes; 14) - Capinar; 15) - Preparar terreno para o plantio; 16) - Plantar; 17) - Cuidar dos animais; 18) - Cuidar da horta; 19) - Cuidar do jardim; 20) - Servente de pedreiro; 21) - Cooperar; 22) - Fazer mandados; 23) - Fazer balaios de bambu; 24) Fazer cestos de barbante; 25) Fazer cestas de cambaúba; 26) - Fazer cestinhas de Jaraguá; 27) Enrestar cebola e alho; 28) - Aprender ofício de sapateiro; 29) - Tomar conta da rouparia; 30) - Cuidar dos alunos mudos (ANTIPOFF; BARBOSA, 1992, p. 131).

A maior preocupação das professoras era a adaptação dos meninos à vida adulta, principalmente, com a escolha da profissão, já que elas constataram que a maioria tinha pouca inclinação para a vida do campo e para o cultivo da terra. Encontramos registro da tentativa de discutir, na 
reunião do Conselho da Fazenda, a questão da escolha da profissão. O diário destacou a dificuldade de se realizar esse tipo de discussão, já que os meninos eram muito calados e não expressavam suas opiniões.

Em 1942, foi construído o internato da "Chacrinha" numa propriedade rural vizinha que foi anexada à Fazenda do Rosário e destinava-se a atender aos meninos de "maior idade". Os trechos dos diários referentes à Chacrinha também enfocaram o trabalho realizado pelos meninos e não deram destaque para as atividades escolares. A única sala do Pavilhão servia de refeitório, sala de jogos, sala de aula e sala de estudos, que se realizavam à noite, não havendo lugar específico para as aulas, o que indica que, nesse novo espaço, as atividades escolares também ficavam em segundo plano. A vida dos meninos não se alterou, a rotina de trabalho continuava muito parecida, pois na "Chacrinha", com exceção da cozinheira, não havia empregados, estando todas as atividades sob responsabilidade dos meninos.

(...) Sem empregados, exceto a cozinheira, todos os trabalhos domésticos, de horta, jardim e de criação de animais e outros se fazia exclusivamente pelos meninos. Obedecendo a uma distribuição semanal de tarefas que se especificava no quadro na única sala servindo de refeitório, sala de aula, de capela, e de salão de jogos e estudos todas as noites - os meninos, no horário previsto, se distribuíam pelas tarefas individualmente, ou em grupos, para cumprir com suas obrigações (ANTIPOFF; BARBOSA, 1992, p. 129).

\section{OS MENINOS DA FAZENDA DO ROSÁRIO: 1940 $-1952$}

Em 1952, Yolanda Barbosa apresentou um balanço do número de alunos atendidos pela instituição desde a sua fundação, constatando que havia lidado com inteligências taradas, com caracteres difíceis, com desajustados, com desamparados e com muitas outras crianças, que constituiu cada uma, um problema social e psicológico para os educadores. Apresentamos, a seguir, os dados referentes ao balanço dos atendimentos nesse período.

Foram atendidos 343 alunos e 121 ainda encontravamse internados; com relação a estes últimos, suas idades variavam de 4 a 18 anos (5 tinham entre 4 e 6 anos, 68 contavam de 7 a 12 anos, 39 estavam com idade entre 13 e 18 anos, 8 tinham a idade desconhecida e 1 tinha mais de 18 anos).

Do total de alunos atendidos, incluídos aqueles que ainda encontravam-se na instituição, 116 alunos, 34\%, foram internados por motivo de abandono social e falta de recursos financeiros, sendo que órfãos de pai e mãe eram 47 e 69 aqueles cujos pais eram desconhecidos. Quanto aos outros 227 internos, foram indicadas outras motivações para a internação, que se referiam ao diagnóstico feito pela Sociedade Pestalozzi, entre os alunos atendidos na capital mineira. No início do ano, a diretora da Fazenda do Rosário notificava o presidente da Sociedade sobre as vagas existentes e este encaminhava à instituição os casos mais urgentes. Muitos meninos foram encaminhados à instituição pela polícia e nada sabiam sobre seus pais, permanecendo na instituição por anos consecutivos sem receber visita de familiares.

(...) Mo., recolhido da rua pela polícia, ainda aos 5 anos, nada sabe dos seus; está na escola há oito anos, sente-se feliz. H., também, enviado à Escola pela polícia, só sabe dos seus que: "morava no morro do Querosene". Há, atualmente, internos na escola, 8 alunos que há mais de 6 anos não recebem visita de parentes ou amigos (BARBOSA apud ANTIPOFF, 1952, p. 07).

O aluno identificado por Mo. foi internado em 1944, aos 5 anos de idade, estava com 13 anos, sendo 8 deles passados na Fazenda. Há casos de alunos que permaneceram mais tempo na instituição, sem nenhum contato com a família. Foi o caso de J.P. que estava internado desde 1941, quando foi retirado pelo delegado do trem, onde estava sozinho com 6 anos de idade. Acreditamos que não havia um critério quanto ao tempo de internação, principalmente para aqueles que não possuíam vínculo familiar.

Os internos foram classificados conforme sua inteligência, baseando-se nos testes psicológicos. De acordo com esses testes, passaram pela instituição 22 "idiotas", 46 "imbecis", 114 "retardados mentais", 75 "normais", 86 não classificados. Helena Antipoff (1992f), escrevendo sobre a caracterização dos "retardados mentais", destacou que esse termo foi introduzido por Alfred Binet ao apresentar um projeto para o funcionamento das classes primárias para "anormais". Dessa maneira, com base em Binet, a educadora pontuou que o indivíduo é assim classificado quando permanece estacionado "num nível inferior ao que caracteriza comumente o desenvolvimento intelectual da massa de uma população a que pertence" (ANTIPOFF, 1992f, p. 185). Destacou que era classificado como "idiota" aquele indivíduo cujo desenvolvimento máximo ia até três anos de idade mental, apresentando incapacidade de se comunicar por meio da linguagem oral organizada. $\mathrm{O}$ "imbecil" apresentaria, além desse quadro, doenças e 'taras' que afetavam o sistema nervoso e o endócrino.

Dos 114 "retardados mentais", Yolanda Barbosa destacou que após dois anos internados, a maioria conseguiu aprender a ler e a escrever, sendo que 21 deles concluíram o ensino primário; 35 tornaram-se operários, pedreiros, 
carpinteiros, empregados do comércio, mecânicos na cidade; 5 casaram-se e constituíram família, conseguindo mantê-la; 33 permaneciam internados na instituição; com relação ao restante, 20 deles, não se conhecia o rumo que tomaram. Daqueles 75 alunos classificados como "normais", 40 ainda encontravam-se na instituição, 1 havia concluído o curso na Escola de Horticultura de Itajubá, 9 estudavam em cursos secundários, 20 encontravam-se exercendo diversas profissões, como comerciário, operário, escritório, trabalhavam em oficinas, 2 faziam parte do serviço militar e, por fim, 3 eram operários e haviam se casado. Dos 22 alunos classificados como "idiotas", a diretora apontou que 4 deles permaneciam internados e não informou o destino seguido pelos outros 18 meninos. Quanto aos classificados como "imbecis", seus destinos eram desconhecidos.

Em 12 anos, foram produzidos 222 egressos e, deste total, a diretora mostrou conhecer a situação de 96 meninos. Estes haviam concluído o ensino primário, trabalhavam como comerciários, operários, pedreiros, carpinteiros, mecânicos, faziam o serviço militar. Yolanda Barbosa fez questão de destacar que 8 meninos tinham se casado e conseguiam manter as suas famílias. Entre todos os egressos, apenas 9 estudavam no ensino secundário e 1 havia terminado o curso na Escola de Horticultura de Itajubá. A maioria dos meninos a que se fez referência quanto à sua vida egressa fazia parte da classe trabalhadora, apenas $5 \%$ desse total havia dado continuidade aos estudos. Percebemos que os egressos foram, principalmente, aqueles classificados como "retardados mentais" e "normais". Assim, inferimos que a diretora da instituição destacou os casos em que a atuação institucional obteve a readaptação e o reajustamento social dos internos, seja por meio da continuidade dos estudos ou pela inserção no mercado de trabalho.

Analisando esses números isoladamente, somos levados a concluir que a Fazenda do Rosário conseguiu a reinserção social de quase metade dos seus internos. Considerando que a instituição formava seus alunos pelo e para o trabalho, podemos dizer que alcançou, mesmo que parcialmente, os seus objetivos. Todavia, faz-se necessário pensar a situação de 126 egressos para os quais não foi possível obter informações. Além disso, não podemos esquecer dos 121 internos que permaneciam na instituição, sem nenhuma perspectiva de saída.

No histórico da Fazenda, apresentado por Helena Antipoff em 1962, a educadora falou desses primeiros anos e assim resumiu as atividades da Escola Dom Silvério e da Chacrinha: “(...) Localizadas em sítios e chácaras, oferecia o internato a seus alunos vários campos de ocupações produtivas e educacionais a uma só vez (...)" (ANTIPOFF, 1992g, p. 275). Resta saber para quem essas ocupações eram produtivas, porque os diários analisados evidenciaram que, para os meninos, essas ocupações não eram produtivas e, muito menos, educativas. Os diários deixaram claro que os meninos não tinham aptidões para os trabalhos no campo, nem tinham preparo físico para tanto. Além disso, não estavam ali por vontade própria, apresentando diversas formas de resistência tanto à internação, quanto aos trabalhos que eram obrigados a realizar. Aqueles que se submetiam ao trabalho, o faziam sob constrangimento imposto pela avaliação de desempenho, à qual estava vinculada a remuneração do trabalho.

As atividades escolares propriamente ditas ficavam em segundo plano, sendo realizadas à tarde e à noite, após os horários de trabalho ou em dias em que o clima não permitia a realização dos trabalhos da fazenda. Além disso, não havia um local específico para ministrar as aulas e o mesmo tratamento era dispensado a todas as crianças, fossem "maiores" ou "menores", "excepcionais orgânicos" ou "sociais". Todos os meninos eram obrigados a fazer um rodízio pelas atividades de limpeza, capina, horta, lavoura, jardim. Um texto escrito por Helena Antipoff (1992d) ajudou-nos a esclarecer para quem essas ocupações eram produtivas.

A assistência ao ser humano infranormal, fraco e desajustado, na coletividade civilizada, não é somente uma prova moral de solidariedade, em que o homem são e forte presta seu auxílio em nome dos princípios perenes de respeito à pessoa humana - é também fruto da convicção de que servindo à criança mesmo que consideravelmente diminuída no seu potencial psíquico por fatores hereditários ou pela ocorrência de acidentes da primeira infância - se realiza uma obra eficiente ao serviço da sociedade (ANTIPOFF, 1992d, p. 140).

$\mathrm{O}$ atendimento aos "excepcionais" representava um serviço à sociedade formando-os moralmente, para que se adaptassem aos padrões sociais e não se transformassem em "rebotalho humano miserável, que enche os hospitais, os manicômios, as prisões" (ANTIPOFF, 1992c, p. 49). Para endossar a importância da formação moral dos meninos "excepcionais", Helena Antipoff reportou-se às classes especiais da Alemanha, cujos ex-alunos compareciam menos aos tribunais judiciários. A assistência aos "excepcionais" prestava um serviço à sociedade na medida em que os preparava para serem capazes de ganhar a vida, tornálos aptos para o trabalho, para que pudessem sobreviver independentes da ajuda do Estado e da sociedade.

Helena Antipoff, após se referir às porcentagens superiores a $90 \%$ de crianças que deixaram as classes especiais na Alemanha, entre 1918 e 1925, e conseguiram 
se empregar em diversos ramos de trabalho, acrescentou que “(...) nossa experiência nos mostrou igualmente a grande adaptação após o curso feito mais devagar, na vida profissional" (ANTIPOFF, 1992d, p. 141).

A formação dos meninos na Fazenda do Rosário visava prepará-los para o trabalho e, para alcançar esse objetivo, o fio condutor das atividades era o próprio trabalho, que substituía os estudos e as brincadeiras e obrigava crianças e adolescentes a se comportarem como adultos trabalhadores, proposição esta que fundamentou, e continua fundamentando, práticas de instituições sócio-educativas dirigidas à infância e juventude pobre no Brasil.

RAFANTE, H. C.; LOPES, R. E. Helena Antipoff and the Rosário Farm: the education by the work for the "exceptional" children and adolescents in 1940s. Rev. Ter. Ocup. Univ. São Paulo, v. 19, n. 3, p. 144-152, set./dez. 2008.

\begin{abstract}
This article is about a historical research, based on documental sources, whose analysis made the history of Rosario Farm emerge. It was an institution created in 1940 by the Russian psychologist and educator Helena Antipoff, to receive, in a boarding school system, "exceptional" children from Belo Horizonte. It was examined the pedagogical actions, the profile and the trajectory of the interns, moreover, the reactions to the institutionalization process - understood as an instrument of dominant sections of society to conserve the current order, with the purpose to detect the different and isolate it, in a structure of social organization that produces contradiction. Under the orientation of this reference, it was verified if the actions applied by Helena Antipoff had taken care of to the necessities of the children and of the institutionalized teenagers or if they were established as an answer to the social environment in which the institution was placed. It was concluded that the formation of the children had for objective making them able for the labor market and the conducting wire of the activities was the work itself that replaced the studies and the games and made them to behave as grown-up workers This education aimed at to the production of the adaptation of the interns to an already-shaped social reality, being, therefore, the education only a path, indeed, to protect and conserve the social order.
\end{abstract}

KEY WORDS: Education, special. Work. Institutionalization. Child institucionalized/education. Disabilities persons/history.

\title{
REFERÊNCIAS
}

ANTIPOFF, H. A Fazenda do Rosário através dos registros. In: ANTIPOFF, H. 'Histórico' da Fazenda do Rosário, escrito por D. Helena em setembro de 1952. Fonte Datilografada. Centro de Documentação da Fundação Helena Antipoff. Ibirité, Minas Gerais. Publicado no Boletim da Sociedade Pestalozzi do Brasil, Rio de Janeiro, 1952.

ANTIPOFF, H. A experimentação natural: método psicológico de Lazursky. In: CDPH (Org.). Coletânea de Obras Escritas de Helena Antipoff - Psicologia Experimental, v. 1, Belo Horizonte: Imprensa Oficial de Minas. Publicado inicialmente em 1927, 1992a.

ANTIPOFF, H. A formação física, intelectual e moral das crianças ao saírem da Escola Pública Primária de Belo Horizonte In: CDPH (Org.). Coletânea de Obras Escritas de Helena AntipoffFundamentos da Educação, v. 2, Belo Horizonte: Imprensa Oficial de Minas. Publicado, inicialmente, em 1932, 1992b.

ANTIPOFF, H. O papel educativo e social das classes especiais. In: CDPH (Org.). Coletânea de Obras Escritas de Helena Antipoff
- Educação do Excepcional, v. 3, Belo Horizonte, Imprensa Oficial de Minas. Publicado, inicialmente, em 1934, 1992c.

ANTIPOFF, H. A função social da assistência às crianças excepcionais. In: CDPH (Org.). Coletânea de Obras Escritas de Helena Antipoff - Educação do Excepcional, v. 3, Belo Horizonte, Imprensa Oficial de Minas. Publicado, inicialmente, em 1946, 1992 d.

ANTIPOFF, H. Sociedade Pestalozzi de Minas Gerais: 1932-1962 - Notas por Helena Antipoff In: CDPH (Org.). Coletânea de Obras Escritas de Helena Antipoff-Educação do Excepcional, v. 3, Belo Horizonte: Imprensa Oficial de Minas, Publicado, inicialmente, em 1963, 1992e.

ANTIPOFF, H. Os Retardados Menais. In: CDPH (Org.). Coletânea de Obras Escritas de Helena Antipoff - Educação do Excepcional, v. 3, Belo Horizonte, Imprensa Oficial de Minas. Publicado, inicialmente, em 1965, $1992 \mathrm{f}$.

ANTIPOFF, H. A Fazenda do Rosário - sua experiência - sua Filosofia. In: CDPH (Org.). Coletânea de Obras Escritas de Helena 
RAFANTE, H. C.; LOPES, R. E. Helena Antipoff e a Fazenda. Rev. Ter. Ocup. Univ. São Paulo, v. 19, n. 3, p. 144-152, set./dez. 2008.

Antipoff - Educação Rural, Vol. 4, Belo Horizonte: Imprensa Oficial de Minas, Publicado, inicialmente, em 1966, 1992g.

ANTIPOFF, H. De Lustro em Lustro: os Jubileus das Três Instituições para Excepcionais - Instituto Pestalozzi de Belo Horizonte, Fazenda do Rosário Ibirité, Sociedade Pestalozzi do Brasil do Rio de Janeiro. In: CDPH (Org.). Coletânea de Obras Escritas de Helena Antipoff-Educação do Excepcional, v. 3, Belo Horizonte: Imprensa Oficial de Minas, Publicado inicialmente em 1965, $1992 \mathrm{~h}$.

ANTIPOFF, H. A Fazenda do Rosário - Sua Experiência - sua Filosofia. In: CDPH (Org.). Coletânea de Obras Escritas de Helena Antipoff-Educação Rural, v. 4. Belo Horizonte, Imprensa Oficial de Minas. Publicado inicialmente em 1966, 1992 i.

ANTIPOFF, H. (1992m). Preparo da Criança para sua Futura Profissão. In: CDPH (Org.), Coletânea de Obras Escritas de Helena Antipoff-Fundamentos da Educação, v. 2. Belo Horizonte, Imprensa Oficial de Minas, Publicado inicialmente em 1932, 1992j.

ANTIPOFF, H.; BARBOSA, Y. Material para estudo da experimentação natural no trabalho - década de 1940: Escola Rural D. Silvério - Outubro de 1943 - Como método de experimentação.
In: CDPH (Org.) Coletânea de Obras Escritas de Helena Antipoff - Educação do Excepcional, v. 3. Belo Horizonte: Imprensa Oficial de Minas, Publicado, inicialmente, em 1943, 1992.

ANTIPOFF, H.; OTTONI, F.; DUARTE, C. Experimentação natural como método para estudo da personalidade e da educação do caráter. Revista Brasileira de Saúde Mental, v. IV. Rio de Janeiro: Oficina Gráfica da Universidade do Brasil, 1958.

BASAGLIA, F.; BASAGLIA, F. Los crimenes de la paz: investigación sobre los intelectuales y los tecnicos como servidores de la opresion. Mexico, Siglo XXI, 1977.

CAMPOS, R. H. F. (Org). Helena Antipoffe a psicologia no Brasil. Belo Horizonte: Autêntica, 2002.

CLAPARÈDE, E. A escola sob medida e estudos complementares sobre Claparède e sua doutrina, por Jean Piaget, Louis Meylan e Pierre Bovet. Rio de Janeiro: Fundo de Cultura, 1953.

RAFANTE, H. C. Helena Antipoff e o ensino na capital mineira: a Fazenda do Rosário e a educação pelo trabalho dos meninos “excepcionais" de 1940 a 1948. 260 p. São Carlos, 2006. Dissertação (Mestrado) - Programa de Pós-Graduação em Educação, da Universidade Federal de São Carlos. 